\title{
A Morphometric Method for Correcting Phytoplankton Cell Volume Estimates
}

\author{
Linda Sicko-Goad, E. F. Stoermer, and Barbara G. Ladewski \\ Great Lakes Research Division, The University of Michigan, Ann Arbor, Michigan, U.S.A.
}

With 3 Figures

Received March 30, 1977

Accepted June 17, 1977

\begin{abstract}
Summary
Cell volume calculations are often used to estimate biomass of natural phytoplankton assemblages. Such estimates may be questioned due to morphological differences in the organisms present. Morphometric analysis of 8 species representative of phytoplankton types found in the Great Lakes shows significant differences in cell constituent volumes. Volume of physiologically inert wall material ranges from nil, in some flagellates, to over $20 \%$ of the total cell volume in certain diatoms. Likewise, "empty" vacuole may comprise more than $40 \%$ of the total cell volume of some diatoms, but less than $3 \%$ of the volume of some flagellates. In the organisms investigated, the total carbon containing cytoplasm ranged from $52 \%$ to $98 \%$ of the total cell volume and the metabolizing biovolume ranged from $30 \%$ to $82 \%$. Although these differences complicate direct biomass estimation, morphometric analysis at the ultrastructural level may provide ecologically valuable insights.
\end{abstract}

\section{Introduction}

Meaningful and reproducible estimation of phytoplankton biomass remains a remarkably complex problem. In the past few years, several investigators have returned to estimates of biovolume in an attempt to escape limitations of traditional secondary measurement techniques since there seems to be a strikingly poor correlation between estimates of phytoplankton biovolume and other independent estimates (VOLLENWEIDER et al. 1974). Biovolume estimates based on species composition, number, and estimated volume have three inherent problems. 1. There is a lack of accuracy in measuring and computing volumes of microscopic, irregularly-shaped, complex forms. 2. There are differing amounts of metabolizing cytoplasm, vacuolar "dead" volume, and resistant wall materials found in different divisions of organisms commonly found in phytoplankton assemblages as well as in different species 
in any particular division. 3. The physiological state of the cell (as a direct result of environmental conditions such as light, temperature, and nutrients, as well as the cell cycle of each organism) may affect both cell size and relative volumes of cytoplasmic constituents within the cell.

Collyer and FogG (1955) demonstrated that different species of algae tend to have similar relative amounts of protein, fats, and carbohydrates when grown under similar environmental conditions. FogG (1966) stated that differences between algal classes with respect to their percent composition tended to be small when compared with the differences a single algal species may show during the course of growth in culture. This demonstrates that both the environment and the growth cycle of the cell are important in determining both biochemical composition and morphology of the cell.

The effects of changes in light intensity on algae have been studied more extensively than any other parameter. Sorokin and Krauss $(1958,1965)$ found that in five green algae, increasing light intensity during growth initially favors cell division. After the optimum light intensity is reached, further increases are inhibitory to cell division. BROWN and RICHARDSON (1968) studied the effects of different growth light intensities on various physiological processes in a variety of algae. They found that the volume of both cells and chloroplasts decreased with increasing light intensity. In most cases, the pigment content varied directly with chloroplast size.

Morphological changes may also occur as a result of changes in the cell cycle and nutrient conditions. Messer and BeN-SHAul (1972) demonstrated that in Peridinium, cell size and chlorophyll content increased during early growth and decreased with culture age. Aged chloroplasts were narrower, had fewer thylakoids, and also had a greater association with endoplasmic reticulum and cytoplasmic ribosomes. They also found that the large number of chloroplasts per cell correlated with a high chlorophyll content. Holmes (1966) demonstrated that in four marine diatoms, nitrate, silicate, and phosphate deficiency resulted in both a reduction in chlorophyll $a$ and a concomitant decrease in the number of chromatophores. The nutrient deficiencies caused a cessation of chlorophyll a synthesis whereas the reduction in chromatophore number was a result of division failure rather than degeneration.

These references demonstrate that the cytology and morphological plasticity of algal cells is affected by environmental conditions. Studies of this type are most easily accomplished by the use of synchronized cultures. However, little effort has been made toward applying the information derived from culture studies to algal species that occur in natural assemblages. The problems associated with studies of naturally-occurring species are numerous. All populations in a natural assemblage of individual species may not be growing optimally at the time of collection. A particular population may exist under quite different environmental conditions during the course of its growth cycle. In relationship to secondary measurement estimates, the 
problems are even more pronounced, since the amount of carbon or chlorophyll per cell may change with the external environment.

During a study of phytoplankton population dynamics and biovolume estimates in Saginaw Bay, it became evident that morphometric methods could be applied successfully to some members of the assemblage in order to arrive at volume estimates of components of ecological significance such as carboncontaining cytoplasm, chloroplast, and "inert" structures. Electron microscopic morphometric methods are based on mathematical developments that consider the probability of obtaining certain two-dimensional profiles from three-dimensional structures by randomly cutting those structures. These methods are commonly used to detect quantitative differences in tissues and cells as an alternative to qualitative differences that might be noted during routine observation. We have utilized these methods to estimate the volume density of cellular components such as cell wall, chloroplast, vacuole (areas devoid of any discernible cytoplasmic component, including gullet, reservoirs, or furrows), storage products, and the remaining cytoplasmic components. The results of the study indicate that the problems associated with biovolume estimates can be both understood, and in many cases, minimized.

\section{Materials and Methods}

All organisms examined in the morphometric analyses were obtained from nearshore Saginaw Bay field samples. Samples of Anabaena flos-aquae were collected from a surface bloom on 9th June 1975 at Station 18 (Lat. $43^{\circ} 44.5^{\prime} \mathrm{N}$, Long. $83^{\circ} 46.4^{\prime} \mathrm{W}$ ) approximately $8 \mathrm{mi}$ from the western shore. All other samples were obtained from collections at Station 56 (Lat. $43^{\circ} 43.8^{\prime} \mathrm{N}$, Long. $83^{\circ} 37.7^{\prime} \mathrm{W}$ ) on 10 th April 1975 , approximately $4.5 \mathrm{mi}$ offshore, and at Station 12 (Lat. $43^{\circ} 38.4^{\prime} \mathrm{N}$, Long. $83^{\circ} 39.7^{\prime} \mathrm{W}$ ) on 3rd May 1975, approximately $2 \mathrm{mi}$ offshore. Water chemistry values and phytoplankton species composition were similar for the two stations during the sampling periods in question. These samples were particularly well-suited for morphometric analysis since the major algal divisions were well represented in the samples and many of the taxa had high standing crops. Water was pumped from a depth of $1 \mathrm{~m}$ into 1 liter polyethylene bottles and was fixed immediately by adding sufficient glutaraldehyde $(50 \%$, biological grade) and sodium cacodylate to give a final concentration of $3 \%$ glutaraldehyde and $0.1 \mathrm{M}$ cacodylate at $\mathrm{pH}$ 7.2. The osmolality of the fixative was 490 milliosmoles. There was little evidence of shrinkage or swelling in the algal cells examined.

Samples were stored on ice and returned to the laboratory within 24 hours for further processing. Samples were then concentrated by gentle centrifugation and rinsed four times in $0.1 \mathrm{M}$ cacodylate buffer, $\mathrm{pH}$ 7.2. The concentrated cells were post-fixed with $1 \% \mathrm{OsO}_{4}$ in $0.1 \mathrm{M}$ cacodylate buffer for 1 hour at $4^{\circ} \mathrm{C}$. The cells were then dehydrated in a graded ethanol $(50 \%, 85 \%, 95 \%, 100 \%)$ and propylene oxide series during a time period of approximately $1 \frac{1}{2}$ hours and then embedded in Epon (LUFT 1961). Thin sections for electron microscopy were cut with a diamond knife, collected on 300 mesh copper grids, and stained with uranyl acetate (STEMPAK and WARD 1964) and lead citrate (REYNolds 1963). Organisms were examined at a standard magnification of either $4,500 X$ or $8,400 X$, depending on taxon cell size, using a Zeiss EM 9 S-2 electron microscope. Magnification calibrations of the microscope were made by use of a grating replica to determine the stability of the standard magnifications. The variation was usually less than $2 \%$. 
Specimens for total cell volume determination were fixed and dehydrated as outlined above, mounted in Epon on glass slides, and viewed using a Leitz Ortholux microscope equipped with a $95 \times$ oil-immersion objective, NA 1.30 or greater.

\section{Quantitative Stereological Methods}

Eight taxa, including representatives from the classes Cyanopbyceae, Bacillariophyceae, Englenophyceae, Cryptophyceae, Dinophyceae and Prymnesiophyceae (HIBBERD 1976) were selected for quantitative analysis. The

Table 1. Sampling Scheme Employed for Morphometric Analysis

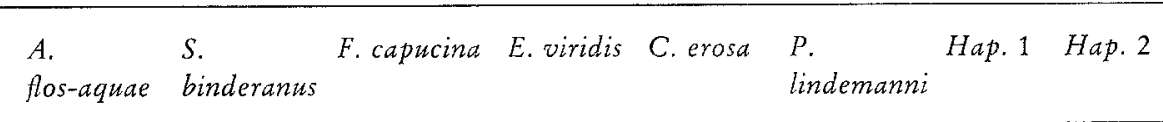

Number of

photos examined 50

46

75

50

75

75

75

75

Final

magnification

25,100

13,600

25,100

13,600

25,100

13,600

25,100

25,100

magnification

Photographic

enlargement

Average No.

Pts/photo

Total Pts

\begin{tabular}{rrrrrrrr}
$8,400 \times$ & $4,500 \times$ & $8,400 \times$ & $4,500 \times$ & $8,400 \times$ & $4,500 \times$ & $8,400 \times$ & $8,400 \times$ \\
$3.0 \times$ & $3.0 \times$ & $3.0 \times$ & $3.0 \times$ & $3.0 \times$ & $3.0 \times$ & $3.0 \times$ & $3.0 \times$ \\
450 & 650 & 450 & 750 & 700 & 1,500 & 450 & 250 \\
23,194 & 30,745 & 33,263 & 38,448 & 54,076 & 111,881 & 32,715 & 20,249 \\
\hline
\end{tabular}

sampling scheme employed was as outlined in Tab. 1. Seventy-five micrographs were examined for each taxon, except where scarcity of a particular taxon in the water samples necessitated a somewhat reduced sample size. In all cases, examination of coefficients of variation and plots of cumulative means and variances indicated adequate sampling of the material. A transparent $0.5-\mathrm{cm}$ square sampling lattice was superimposed over the micrographs for quantitative measurements. This sampling lattice was chosen to estimate the rarest components across all species. Since the cytoplasmic arrangement was not known prior to the study, a double lattice was not utilized.

The first identifiable occurrence of each taxon on a grid was photographed. Identification or selection of organisms was not based on the presence or absence of particular cellular organelles. However, small grazing sections may be slightly undervalued in the samples due to problems associated with species identification. Grazing tip sections containing only cell wall or cell wall with no identifiable features of the algal cells were not included in the analysis. The frequency of occurrence of such small tip grazing sections was very low. Blocks were retrimmed after each series of sections was cut, in order to avoid 
repeated sampling of adjacent material within the same organism. For filamentous taxa (e.g., F. capucina, S. binderanus, A. flos-aquae), a single cell was randomly selected from each filament. The largest cross-sectional area of several of the taxa examined exceeded the photographic field of view at the standard magnification chosen. In these cases subsamples of the largest encountered cross-sections were photographed with the grid bars as reference markers, using the upper left portion of the first field, the upper right portion of the next, the lower left, then the lower right, etc.

Table 2. Cell Volume Estimates for the Eight Phytoplankton Species Examined

\begin{tabular}{lrrl}
\hline Taxon & Volume $\mu \mathrm{m}^{3}$ & (SE) & Formula \\
\hline Anabaena flos-aquae & 80 & $(9) \pi d^{2} b / 4$ \\
Stephanodiscus binderanus & 830 & $(92) \pi d^{2} b / 4$ \\
Fragilaria capucina & 400 & $(37) \quad b l b$ \\
Euglena viridis & 3,100 & $(450) \pi l_{1} b_{1}^{2} / 6+\pi l_{2} b_{2}^{2} / 4 *$ \\
Cryptomonas erosa & 1,300 & $(250) \pi l b^{2} / 6$ \\
Peridinitum lindemanni & 11,000 & $(2,100) \pi l b^{2} / 8 * *$ \\
Haptopbyte 1 & 100 & $(20) \pi d^{2} b / 4$ \\
Haptophyte 2 & 70 & $(7) \pi d^{2} b / 4$ \\
& & &
\end{tabular}

$b=$ breadth, $l=$ length, $b=$ height, $d=$ diameter

* Euglena was assumed to be a composite geometric shape consisting of a rotation ellipsoid with major axis of rotation $l$, and minor axis $b$, and a smaller cylinder of height $l_{2}$ and average diameter of $b_{2}$.

$*$ Peridinium was assumed to be intermediate in volume between a rotation ellipsoid with major axis of rotation $l$ and a composite shape consisting of two cones each of height $l / 2$.

Estimates of volume density, i.e., the fractional volume of a cellular component related to its containing volume were obtained using both the paper profile cut-and-weigh (Delesse 1847) and grid point-counting (GlagolefF 1933, Chalkey 1943) techniques. Although both methods were found to yield similar estimates of volume density, point-counting was found to be easier and faster to implement. Except where specifically indicated, reported morphometric results will be those derived from the point-counting technique.

The point-counting method is an extension of the Delesse principle which states that the areal density of profiles on "two-dimensional" sections is an unbiased estimate of the volume density of the corresponding structures within the tissue (Delesse 1847 cited in WeIbel and Bolender 1973), i.e.,

$\frac{V_{i}}{V_{T}}=\frac{A_{i}}{A_{T}}=\frac{P_{i}}{P_{T}}$

where $V_{i}=$ volume of a component $i, A_{i}=$ area of $\mathrm{i}$ in a section, $P_{i}=$ number of points falling within the boundary of $i, V_{T}=$ total containing 
volume, etc. (Notation and definitions are those of WeIBEL and Bolender 1973.) Thus, by counting points of a sampling grid striking component $i$, or by weighing the area of $i$ on a two-dimensional section and comparing that quantity with a containing area measured in the same units, an unbiased
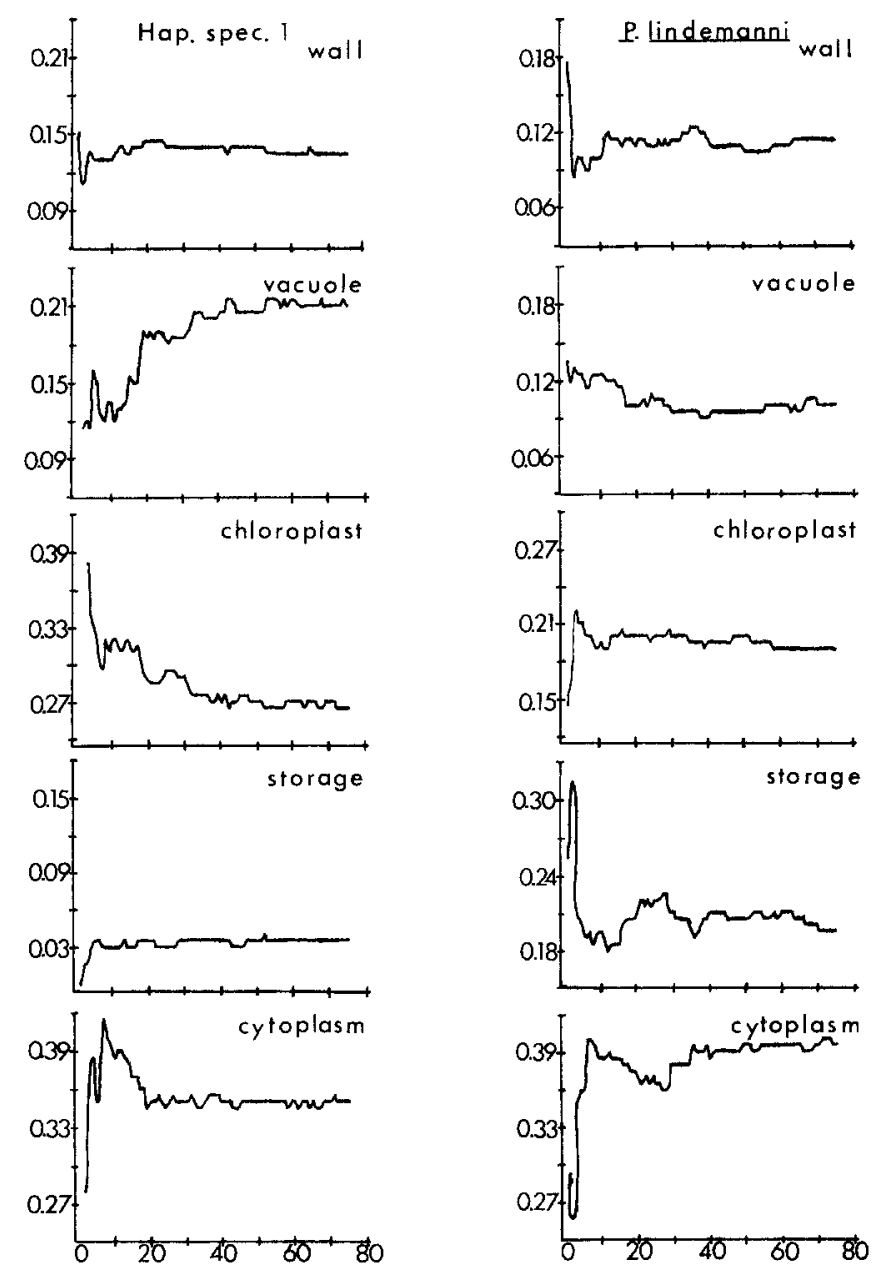

Fig. 1. Cumulative mean (percent volume) as a function of sample size (number of micrographs) for 5 cytoplasmic components of $P$. lindemanni and Hap. 1

estimate of the volume fraction of component $i$ in the original tissue can be obtained. Additional information concerning the more theoretical aspects of stereology can be found in one of several excellent reviews on the subject (Loud 1968, UNDER wood 1970, WeIBel and Bolender 1973).

Actual cell volume estimates $\left(\mu \mathrm{m}^{3}\right)$ were obtained from light microscopic examination of cells obtained from the same assemblages as those used for the quantitative stereological analysis. Estimates are based on 10 independent 


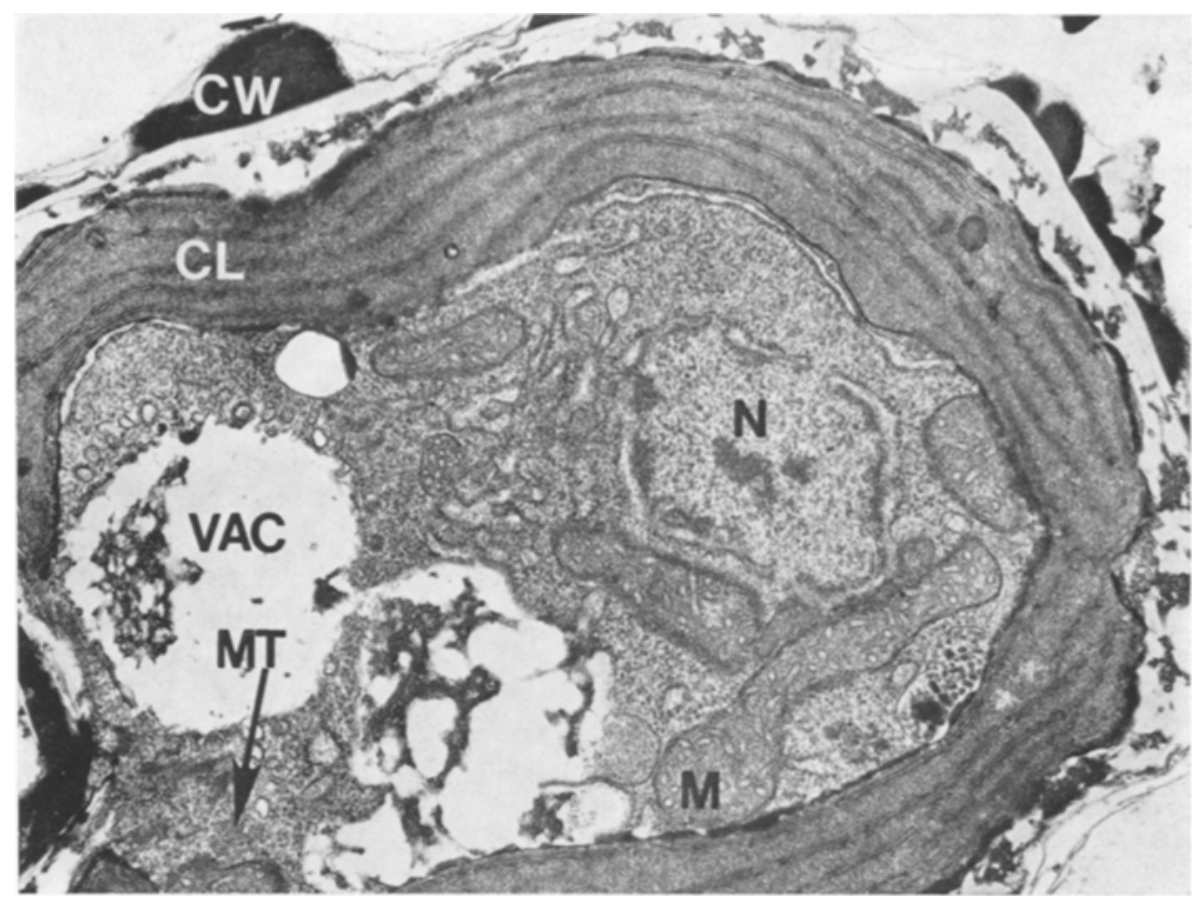

Fig. 2. Undetermined Prymnesiophycean Alga (Hap. 1). Micrograph shows parietal chloroplast and polar vacuolar region. $(C W)$ cell wall; $(N)$ nucleus; $(M)$ mitochondrion; $(V A C)$ vacuole; $(C L)$ chloroplast; $(M T)$ microtubules. $\times 25,700$

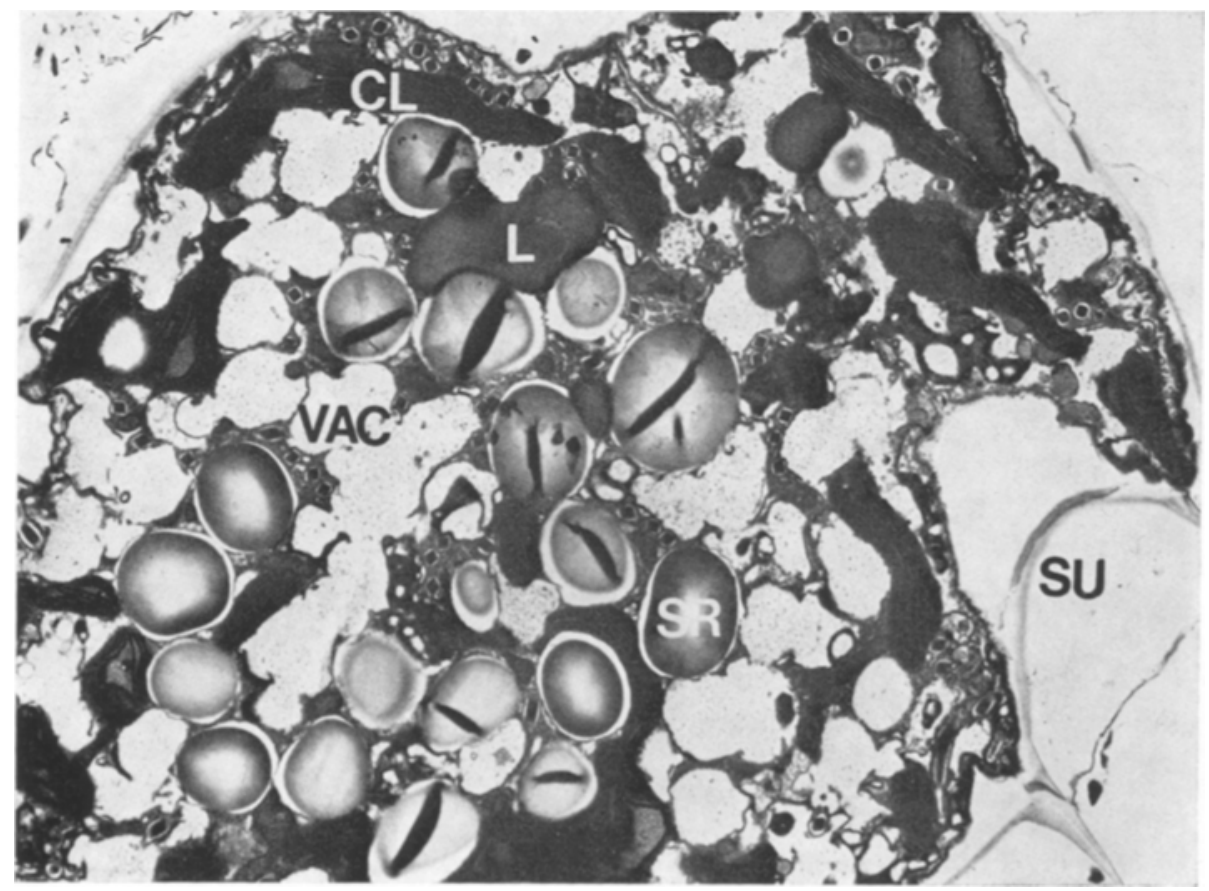

Fig. 3. Peridinium lindemanni. $(S U)$ sulcus; $(S R)$ storage. $\times 6,500$ 
measurements for each taxon, and assume a regular geometric shape for the taxon (Tab. 2). Specific geometric formulae used in the volume calculations are also presented there.

Statistical analyses were performed with the assistance of the MIDAS statistical routines available through the computing facilities at the University of Michigan. Parameter estimates are reported as the mean \pm standard error unless specifically designated otherwise.

\section{Results}

\subsection{Sample Size Determination}

Plots of the cumulative mean and variance as a function of the number of micrographs examined were used to evaluate the adequacy of the micrograph sample size used in the morphometric analysis (Chalkey 1943). The order of micrographs was randomized prior to mean calculation and plotting. Micrographs were then re-randomized and plotted a second time to check that the plateau observed for the mean or variance was in fact stable and not a function of the order of micrographs. The cumulative means for the largest organism studied, $P$. lindemanni, and the smallest, Haptophyte sp\#1, are presented in Fig. 1. Such plots demonstrate that the apparent requisite sample size will differ from organism to organism and from component to component within a given organism. Components that tend to be highly oriented, such as the Haptophyte chloroplast or vacuole (Fig. 2), require a large number of random sections to characterize their volume fraction; components that tend to be more uniformly dispersed throughout the cell, e.g., the dinoflagellate chloroplast (Fig. 3), seem to stabilize rather quickly. Most cellular components for the organisms examined in this study were adequately characterized by $30-50$ random micrographs.

\subsection{Filament Analysis}

A preliminary pilot survey utilizing stereological cut-and-weigh techniques was undertaken to evaluate the bias introduced by sampling more than one cell from a given filament. Two factors suggest a possible bias in selecting cells from the same filament: 1 . cells in a given filament are genetically and developmentally related; and 2 . since cells in the same filament have been sectioned at the same angle, the primary stereological assumption of randomness of sectioning angle has been violated. However, since ease of sampling favors multiple samples from a single filament, the question was examined statistically.

Fifty-two electron micrographs-representing 13 filaments of the diatom $F$. capucina, with 4 adjacent cells sampled per filament-were measured using the stereological cut-and-weigh technique. The volume fractions obtained for frustule, storage and cytoplasm for each of the thirteen filaments were com- 
pared using a one-way univariate analysis of variance (4 replicates per anova cell). The results are summarized in Tab. 3 . All three analyses indicate that the between filament variance is significantly larger than the within filament variance. Examination of mean cellular volume fractions for the 52 micrographs compared with means obtained from a sample of 13 micrographs, one randomly chosen from each filament, show little difference between the two parameter estimates. Therefore, preliminary evidence seems to indicate that

Table 3. Analysis of Variance (Anova) of Between and Witbin Filament Variance

\begin{tabular}{lllll}
\hline Source & DF & Sum of squares & Mean square & F-Stat \\
\hline $\begin{array}{l}\text { Anova-frustule fraction } \\
\quad \text { Between filaments }\end{array}$ & 12 & 0.11900 & 0.0099167 & $10.620^{1}$ \\
$\quad$ Within filaments & 39 & 0.036417 & 0.00093377 & \\
$\begin{array}{l}\text { Anova-storage fraction } \\
\quad \text { Between filaments }\end{array}$ & 12 & 1.0297 & 0.085811 & $89.631^{1}$ \\
$\quad$ Within filaments & 39 & 0.037337 & 0.00095737 & \\
$\begin{array}{l}\text { Anova-cytoplasmic fraction } \\
\quad \text { Between filaments }\end{array}$ & 12 & 1.3666 & 0.11388 & $29.381^{1}$ \\
$\quad$ Within filaments & 39 & 0.15117 & 0.0038762 & \\
\hline
\end{tabular}

1 Significant at 0.001 level.

multiple samples from a single filament do not substantially improve volume estimates for the given filament and may potentially bias the population estimate if differing numbers of cells are sampled per filament.

\subsection{General Descriptive Measures}

The quantitative results presented in this study describe both physical and physiological "compartments" of the cell. In general, the following categories and their limits have been utilized (the sum of the starred components should be $100 \%$ ):

1.* Wall/Frustule: area outside of the plasma membrane.

2.* Vacuole: vacuole area of the cell bounded by the vacuolar membrane (tonoplast). This category may also include storage located in this region.

2 a. Vacuole Storage: that portion of the total vacuole volume which is storage (generally lipids in the diatoms).

2 b. "Empty" Vacuole: total vacuole vacuole storage.

3.* Chloroplast: chloroplast volume; also includes any pyrenoid and chloroplast storage products such as lipids and starch, if they are present.

3 a. Chloroplast Storage: storage within the chloroplast; pyrenoid and starch.

3 b. "Naked" Chloroplast: total chloroplast chloroplast storage. 
4.* Cytoplasmic Storage: storage material (starch, lipids, oils, paramylon, etc.) located in the cytoplasm. Does not include vacuole or chloroplast storage.

5.* Cytoplasm: all cellular components not included in one of the above categories (includes organelles such as golgi, nucleus, ejectosomes, mitochondria, etc.).

6. Total Storage: sum of $2 a, 3 a$, and 4 .

7. Total Carbon-Containing Cytoplasm: storage and cytoplasm and chloroplast ( $3 \mathrm{~b}, 5$, and 6 ) (does not include vacuole or wall).

8. "Metabolizing" Biovolume: cellular components that are active metabolically; cytoplasm and chloroplast (does not include vacuole, wall, or storage).

Summaries of the quantitative results are presented in Tabs. 4 and 5. The following points were noted for the individual species:

Anabaena flos-aquae: Inappropriate field fixation and the resultant collapse of individual gas vesicles probably has led to an underestimation of the relative volume of the "pseudovacuole" category. No attempt was made to select for cyanophycin granules or polyphosphate bodies in the micrographs; therefore the values obtained should be an unbiased estimate of the occurrence of these inclusions within the field population. The extremely low volume fractions may be indicative of the environmental conditions at the time of sampling.

Stephanodiscus binderanus and Fragilaria capucina: As might be expected, the volume fraction of frustule was higher in $F$. capucina than in S. binderanus. Both diatoms have a large volume fraction of vacuole as well as lipid in the vacuole. Another common feature between the diatoms is the percentage of carbon-containing cytoplasm, which is slightly larger than $50 \%$.

Euglena viridis: The most noticeable feature encountered in Euglena was the high percentage of storage products (Paramylon). The reservoir (vacuole) and the contractile vacuole accounted for a higher volume fraction than was expected $(16 \%)$. The pellicular ridges also occupied approximately the same volume fraction as the frustule in Stephanodiscus and the cell wall in Anabaena.

Cryptomonas erosa: The three major divisions of cellular compartments accounting for $92 \%$ of the volume of Cryptomonas were cytoplasm, chloroplast, and storage products. The remaining $8 \%$ of the volume was the anterior furrow and gullet. Consequently, Cryptomonas had one of the highest carbon-containing cytoplasm values.

Peridinium lindemanni: $P$. lindemanni had a total storage volume percent that was near the middle of the range across all eight species. This was not obvious from the pictures; the dinoflagellates had many small starch grains and lipid droplets.

Prymnesiophycean Algal Species 1 and 2: The differences between these species was as great as the differences between the diatoms examined. Total 


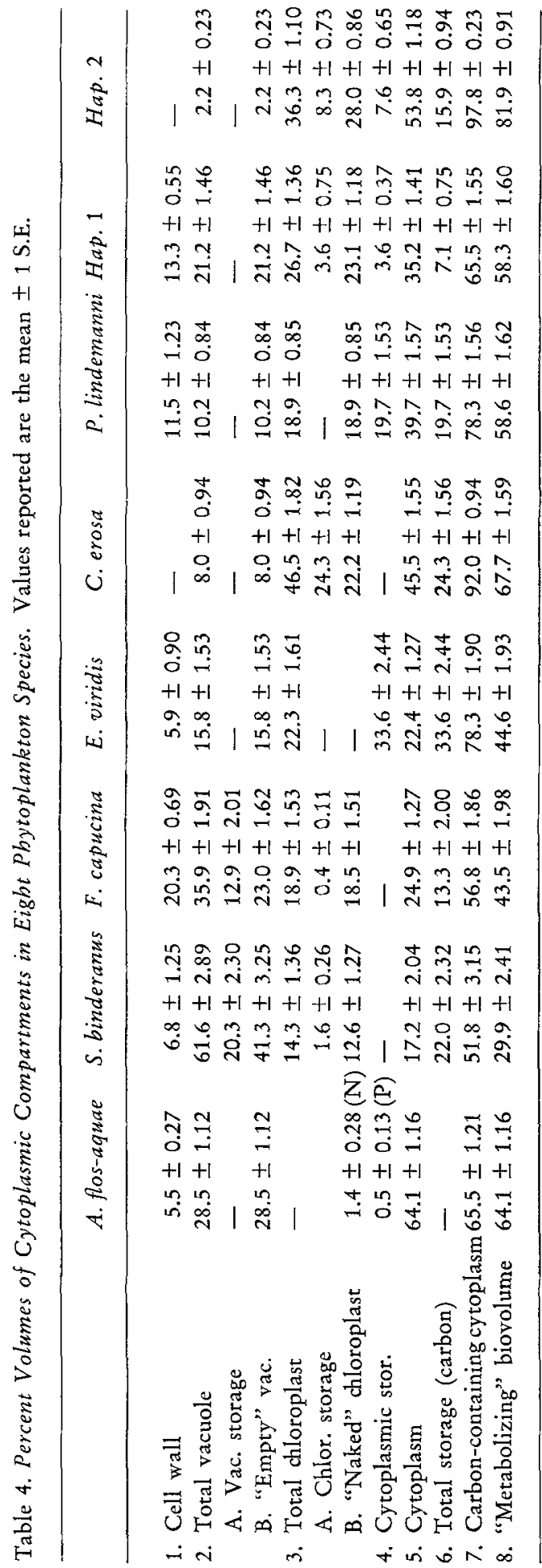


vacuole differed by a factor of 10 ; the wall volume percents were $13.0 \pm 0.55$ and nil; the total storage differed by a factor of 2 .

\section{Discussion}

AtKinson et al. (1974) first utilized electron microscopic morphometric methods to determine the volume fraction of certain cellular compartments in Chlorella. They demonstrated that cellular organelles were able to grow continuously throughout the cell cycle. Consequently, the average volume percents were $40 \%$ for chloroplast, $3 \%$ for the mitochondrion, and $10 \%$ for

Table 5. Absolute Volumes $\left(\mu^{3}\right)$ and Standard Errors of Defined Areas in the Algae. Numbers were calculated using the morphometrically-derived percentages found in Table 4 for these components, and the absolute volumes of the organisms calculated by assuming a regular geometric figure (Table 2 )

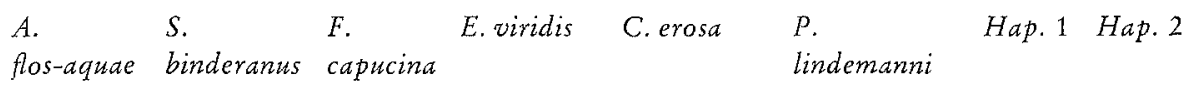

Total carboncontaining

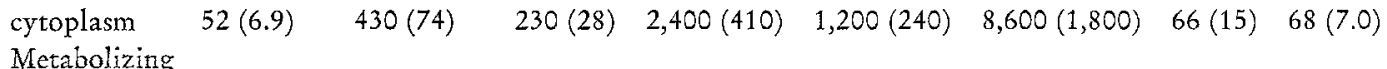
biovolume $\quad 51(6.7) \quad 250(48) \quad 170(24) \quad 1,400(260) \quad 880(190) \quad 6,400(1,400) \quad 58(13) \quad 57(6.4)$ Naked

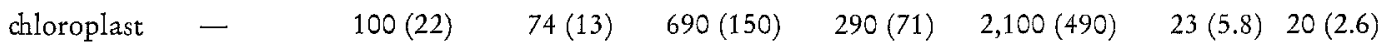

vacuoles and nucleus throughout the cycle. The components that were of particular interest were the vacuole, starch, and pyrenoid. Because Chlorella contains no large central vacuole, it had previously been assumed that the area of the tonoplast was insignificant. The authors confirmed that the tonoplast has an area equal to at least a third of the plasmalemma area. This indicates that the small vacuoles randomly scattered throughout the cytoplasm do contribute significantly to the total cell volume as well as to the tonoplast area, which is also believed to contribute to solute absorption in plant cells (Laties 1969, Humphreys 1973).

AtKinson et al. (1974) also correlated starch reserves to respiratory activity of the cell. Starch appeared to function as a reserve material that sustained cytokinesis in the absence of photosynthesis. The onset of photosynthesis resulted in a recovery of starch reserves that were depleted during cytokinesis in the dark phase of cell synchronization. Consequently starch reserves were quite dependent on both the photosynthetic and respiratory activities of the cell.

The morphological characteristics of algae are highly dependent upon a wide 
variety of environmental parameters. Although these parameters can be easily regulated in a culture situation, the effects produced in culture studies are not easily applied to natural assemblages where a wide variety of environmental conditions may be changing simultaneously. Biovolume estimates are used to assess the importance of algal species since phytoplankton standing crop is often converted to biomass through cell volume determinations (NalewajKo 1966). Cell volume data are also used to extrapolate to organic carbon content, ash-free dry weight, and chlorophyll (PAAsche 1960, MuLLiN et al. 1966, StrathMANn 1967).

We feel that our results indicate that the inherent cellular organization of some species contributes significantly to the error of such biomass calculations. This problem was first recognized by Lohmann (1908) who indicated that only a small proportion of a large diatom is occupied by chloroplasts and cytoplasm, with the remainder of the cell being vacuole. LoHMANN (1908) suggested that this should be taken into account when comparing the productive capacity of cells and their cell volumes, since the cytoplasm may form only a layer of $2 \mu \mathrm{m}$ around the cell periphery. Paasche (1960) and StrathMANN (1967) have both used such correction factors and found that cell carbon, in many instances, correlates better with surface area than cell volume for diatoms. These techniques have also been utilized recently by BeLLINGER (1974).

The morphometric methods utilized in the present study demonstrate that both cell vacuole and cell wall play an important role as "inert" structures in all the algal species examined, not only the diatoms. In Tab. 5, we have calculated the corrected cellular volumes of carbon-containing structures in the cell, metabolizing biovolume (that portion of the cell other than inert structures such as cell wall and vacuole, and storage products) and chloroplast volume. When one does not include cell wall or vacuole in the volume estimates, the carbon-containing cytoplasm percentage drops significantly. Consequently, correction factors are not only applicable to large diatoms. Small vacuoles scattered throughout the cytoplasm may substantially alter biomass and cell carbon estimates.

One of the most important features of the morphometric study is that the eight algal species were all taken from water masses with similar chemical and physical properties. Consequently, the number of environmental parameters that have been demonstrated in the literature to affect the cytology of a variety of organisms is reduced. Although we are not sure that all algal species were growing under optimal conditions, it is likely that the results presented here more closely resemble the percentages that would be found in naturally-occurring assemblage during the spring quarter than would cultured algal species. In this respect, the corrected biovolume estimates as presented are better than those derived by use of geometrical formulae alone.

The most obvious example of corrected biovolume estimates from our data 
is the case of the two diatoms, $S$. binderanus and $F$. capucina. The quantitative results show that in both species of diatoms, over $40 \%$ of the cell is occupied by frustule and vacuole. These two taxa also exhibit large significant differences in both frustule and vacuole relative volumes, even though they belong to the same "physiological" group. Such data suggest that cell volumes derived from geometrical formulae may differ significantly from the real quantity being sought, such as mg cellular carbon or metabolizing biomass, and the correction factor is probably not a constant for a given class of algae. Since, of all the groups examined in this study, wall and vacuole categories attain their largest cellular fractions in diatoms, errors in cell volume calculations based on shape will be particularly large in systems such as the Great Lakes where diatoms comprise a significant part of the assemblage.

Only a small fraction of the total storage in both diatom species is associated with the chloroplast. The remaining storage products, $13-20 \%$ of total cellular volume, were localized within the vacuole; approximately half of the vacuolar area in both taxa was occupied by storage. Since storage products are known to accumulate in senescent cells, percent storage may be a useful indicator of cell growth conditions.

We feel that this study of cell volume components is important for several reasons:

1. The chemical composition across algal phyla varies. This is especially significant in species that possess non-metabolizable mineralized scales or walls, which make up a considerable percentage of the total cell volume.

2. The cytological characteristics of the numerous algal species also varies. Consequently, the percentage of various components, such as vacuole, is not consistent either between phyla or between similar species.

3. Cytological compartments or volumes are subject to change with changing environmental parameters. Certain features, such as the presence of large amounts of storage products, are indicative of senescent cells. The use of morphometric methods allows one to detect morphological changes that might otherwise go undetected. One does not have to rely solely on gross morphological changes to detect significant differences between cells.

The use of stereological techniques with natural phytoplankton assemblages presents problems that are unique to this method of analysis. Two difficulties encountered with the present analysis were related to the fact that the assemblage does not consist of a homogenous group of organisms, but rather consists of populations of organisms that are quite different. The individual populations comprising the assemblage may be either unicellular or colonial. The filament analysis presented in this study indicated that pictures of cells which are from the same filament cannot be treated as individual random samples of a population of cells because the cells are physically linked together. A particular random section angle through one cell in a filament will 
determine the same angle through another cell in that filament. The problem is evident with the diatoms examined in this study because the filament is structurally quite rigid. It would appear that the problem would be less severe in a filamentous blue-green where the filaments are not so rigid and can twist, or in some cases, even form a gelatinous ball as the colony shape. In no case can two adjacent cells in a filament be utilized as random samples since the cells are genetically and developmentally related.

The sample assemblages chosen were particularly well suited for stereological analysis since the species analyzed were quite abundant, minimizing the number of random sections which are essential for stereology. On 10th April 1975 , the analyzed species accounted for $56 \%$ of the numbers of organisms present in the sample and $96.2 \%$ of the cell volume as determined by classical light microscopic methods. On 3rd May 1975, 54\% of the assemblage and $80.5 \%$ of the cell volume of phytoplankton were contributed by the species analyzed. Since the organisms analyzed accounted for such a large percentage of the assemblage both by numbers and biovolume, the possibility of errors introduced by misidentification within genera was also minimized. Reliable cell carbon data is not available for these samples. Consequently, we have made no attempt to compare the corrected cell volume data to total carbon and determine the correlation between these figures.

Individual grazing tip sections of the organisms analyzed from the assemblage also presented a minor problem with the stereological analysis. The organisms studied were members of six different divisions of algae, all quite distinct structurally. Anabaena is a prokaryote. Stephanodiscus and Fragilaria possess siliceous frustules. Peridinium possesses thecal plates and has a distinctive nuclear structure. Euglena has a distinctive pellicle and paramylon granules. The Prymnesiophycean algae possess haptonema, bundles of microtubules, and may have small organic scales. Most of these features are evident in all sections except the extreme grazing sections. The problem with the grazing sections was most pronounced in the diatoms where only a small portion of the frustule with no distinctive arrangement of the siliceous plates was present. However, only a very small percentage of such sections was encountered. In most cases, the grazing sections possessed enough structure to distinguish between the two organisms. Similarly, the organisms that possessed only a single membrane at the periphery of the cell (Cryptomonas and Hap. 2) presented the same problem. Considering the organization and size of the cells, the amount of cytoplasm that was underestimated by not selecting those extreme grazing sections through the outer membrane was negligible.

Studies are presently being undertaken in which the quantitative evaluation of the cellular compartments of all phytoplankton in the assemblage are measured with each organism being considered a random sample of the assemblage total carbon. 


\section{Acknowledgements}

Sincere appreciation is extended to Dr. ALDEN V. LovD for offering suggestions during the course of the study and for critically reading the manuscript, and to Ms. ANN Slubowski Davis and Ms. Diane Lazinsky for technical assistance. Supported by Environmental Protection Agency grant number R-802280-02-02. Great Lakes Research Division Contribution Number 224.

\section{References}

Atrinson, A. W. JR., P. C. L. John, and B. E. S. Gunning, 1974: The growth and division of the single mitochondrion and other organelles during the cell cycle of Chlorella, studied by quantitative stereology and three dimensional reconstruction. Protoplasma 81, 77-109.

Bellinger, E. G., 1974: A note on the use of algal sizes in estimates of population standing crops. Br. Phycol. J. 9, 157-161.

Brown, T. E., and F. L. Richardson, 1968: The effect of growth environment on the physiology of algae: Light intensity. J. Phycol. 4, 38-54.

Chalkey, H. W., 1943: Methods for the quantitative morphologic analysis of tissues. J. nat. Cancer Inst. 4, 47.

Collyer, D. M., and G. E. Fogg, 1955: Studies on fat accumulation by algae. J. exp. Bot. 6, $256-275$.

Delesse, M. A., 1847: Procédé mécanique pour determiner la composition des roches. C. R. Acad. Sci. (Paris) 25, 444.

FogG, G. E., 1966: Algal cultures and Phytoplankton ecology, 126 pp. Madison, Wisconsin: University of Wisconsin Press.

GlagolefF, A. A., 1933: On the geometrical methods of quantitative mineralogic analysis of rocks. Tr. Inst. Econ. Min. and Metal, Moscow. Volume 59.

Hibberd, D. J., 1976: The ultrastructure of the Chrysophyceae and Prymnesiopbyceae (Haptophyceae): a survey with some new observations on the ultrastructure of the Chrysopbyceae. Bot. J. Lin. Soc. 72, 55-80.

Holmes, R. W., 1966: Light microscope observations on cytological manifestations of nitrate, phosphate, and silicate deficiency in four marine centric diatoms. J. Phycol. 2, 136-140.

Humphreys, R. E., 1973: Sucrose transport at the tonoplast. Phytochem. 12, 1201-1219.

Laties, G. G., 1969: Dual mechanisms of salt uptake in relation to compartmentation and long distance transport. Ann. Rev. Plant Physiol. 20, 89-116.

LohmanN, H., 1908: Untersuchungen zur Feststellung des vollständigen Gehaltes des Meeres an Plankton. Wiss. Meeresuntersuch. Abt. Kiel N. F. 10, 131-370.

Loud, A. V., 1968: A quantitative stereological description of the ultrastructure of normal rat liver parenchymal cells. J. Cell Biol. 37, 27-45.

Lufr, J. H., 1961: Improvements in epoxy resin embedding methods. J. biophys. biochem. Cytol. 9, 409-414.

Messer, G., and Y. BeN-Shaul, 1972: Changes in chloroplast structure during culture growth of Peridinium cinctum Fa. Westii (Dinopbyceae). Phycologia 11, 291-299.

Mullin, M. M., P. R. SloAn, and P. W. Epplex, 1966: Relationship between carbon content, cell volume, and area in phytoplankton. Limnol. Oceanogr. 11, 307-311.

NALEWAjKo, C., 1966: Dry weight, ash, and volume data for some freshwater planktonic algae. J. Fish. Res. Bd. Can. 23, 1285-1288.

PaAscue, E., 1960: On the relationship between primary production and standing stodk of phytoplankton. J. Conseil, Conseil Perm. Intern. Exploration Mer. 26, 33-48.

Reynolds, E. S., 1963: The use of lead citrate at high $\mathrm{pH}$ as an electron opaque stain in electron microscopy. J. Cell Biol. 17, 208-212. 
Sorokin, C., and R. W. Krauss, 1958: The effect of light intensity on the growth rates of green algae. Plant Physiol. 33, 109-113.

- 1965: The dependence of cell division in Cblorella on temperature and light intensity. Amer. J. Bot. 52, 331-339.

Stempak, J. F., and R. T. WARD, 1964: An improved staining method for electron microscopy. J. Cell Biol. 22, 697-701.

StrathmanN, R. R., 1967: Estimating the organic carbon content of phytoplankton from cell volume or plasma volume. Limnol. Oceanogr. 12, 411-418.

UNDER WOOD, E. E., 1970: Quantitative Stereology, 274 pp. Reading, Mass.: Addison-Wesley.

Vollenweider, R. A., M. Munawar, and P. Stadelmann, 1974: A comparative review of phytoplankton and primary production in the Laurentian Great Lakes. J. Fish. Res. Bd. Can. 31, 739-762.

Weibel, E. R., and R. B. Bolender, 1973: Stereological techniques for electron microscopic morphometry. In: Principles and techniques of electron microscopy. Biological Applications (HAYAT, M. A., ed.), Volume 3, pp. 239-296. New York: Van Nostrand Reinhold.

Authors' address: Linda Sicko-Goad, Great Iakes Research Division, The University of Michigan, Ann Arbor, MI 48109, U.S.A. 